\title{
Não contradição ou terceiro excluído? Avicena e o primeiro princípio da metafísica
}

\author{
Alfredo Storck \\ alfredostorck@gmail.com \\ Universidade Federal do Rio Grande do Sul - CNPq, Porto Alegre, RS, Brasil
}

resumo Em sua paráfrase da Metafisica de Aristóteles, Avicena parece adotar um primeiro princípio diferente do adotado pelo filósofo grego para essa ciência. De fato, alguns intérpretes consideram que ele prefere o princípio do terceiro excluído em vez do princípio de não contradição. Como discordo dessa tese, proponho-me analisar aqui a formulação de Avicena do primeiro princípio.

palavras-chave necessidade; contradição; futuros contingentes; Aristóteles; Avicena; Lukasiewicz

O oitavo capítulo da primeira parte do Liber de Philosophia Prima é consagrado à apresentação dos primeiros princípios da metafísica. Ora, dada, de um lado, a estratégia geral de Avicena de reelaborar a estrutura da metafísica aristotélica e, de outro, o fato de o livro Gama da Metafísica de Aristóteles abordar precisamente o mesmo tema, pode-se perguntar se o filósofo persa segue o grego ou se prefere modificar os fundamentos no momento de estabelecer os princípios da disciplina suprema. A primeira vista, a questão não parece trazer dificuldades. A relativa brevidade de Avicena, os pontos comuns entre os dois autores e os silêncio dos intérpretes poderiam servir de indício para concluir o acordo entre os dois pensadores. Gostaríamos, no entanto, de sugerir que a situação não é assim tão simples. Para tanto, buscaremos apontar algumas dificuldades que dizem respeito sobretudo à determinação do primeiro princípio da metafisica. Ainda que permaneça silente sobre suas razões, Avicena é 
considerado pela literatura especializada como se afastando das lições aristotélicas e como propondo uma formulação distinta do primeiro princípio. Interessa-nos analisar o significado dessa modificação. Trata-se verdadeiramente de um desacordo conceitual ou, como acreditamos, apenas da enunciação alternativa do mesmo princípio?

$\mathrm{Na}$ maior parte dos casos, os intérpretes de Avicena têm deixado a pergunta intocada. A exceção mais significativa pode ser encontrada na Introduction doctrinale que G.Verbeke escreve para a edição crítica latina e que sugere uma real divergência entre Aristóteles e Avicena acerca dos primeiros princípios. Como é bem conhecido, em Gama 3, 1005b19, Aristóteles afirma ser o seguinte o princípio mais certo: "É impossível que o mesmo atributo pertença e não pertença ao mesmo tempo ao mesmo sujeito e sob o mesmo aspecto". Em Gama 4, apresenta uma defesa do princípio, tradicionalmente conhecido como "princípio de não contradição", oferecendo sete razões para sua aceitação. Após ter criticado Protágoras (Gama 5 e 6), acrescenta sete novas razões para um segundo princípio ${ }^{2}$, tradicionalmente conhecido como "princípio do terceiro excluído" e formulado em Gama 7, 1011b23, nos seguintes termos: "Não é possível também que haja um intermediário entre os dois enunciados contraditórios, mas é preciso necessariamente afirmar ou negar um predicado qualquer de um sujeito". Apoiando-se nessa divisão do texto aristotélico, VERBEKE (1973, p. 37^) sustentou que Avicena "adota como juízo primeiro o princípio do terceiro excluído". A tese possui uma significação clara. Em primeiro lugar, sem explicitar suas razões, o filósofo persa teria modificado a ordem entre os princípios proposta por Aristóteles. Em seguida, teria sustentado a validade do PTE valendo-se precisamente dos argumentos avançados pelo Estagirita em favor do PNC. Essa interpretação apresenta uma dificuldade que merece ser analisada. Ou bem é Avicena que, sem fornecer a menor explicação, inverte os textos e utiliza os argumentos em favor de um princípio para provar o outro, provavelmente porque, nos Segundos Analíticos o PNC é mais citado do que o PTE (BERTOLACCI 2006, p. 391), ou bem simplesmente não é correto afirmar que o PTE é o primeiro princípio da metafísica aviceniana.

Confrontado ao problema, o intérprete deve posicionar-se: aceitar a tese de $\operatorname{VERBEKE}(1973$, p. 38*) e precisar as razões para a mudança 
explicando as raízes do desacordo ou negar que "na óptica de Avicena o princípio do terceiro excluído é verdadeiramente primeiro". Ora, para que a interpretação de Verbeke seja convincente, é preciso que Avicena: a) considere os dois princípios como distintos; b) possua razões para preferir o PTE. Acreditamos ser essa interpretação excessiva. Não há motivos para separar tão nitidamente os dois princípios no interior da filosofia aviceniana. Diríamos, antes, que os dois princípios devem ser tomados conjuntamente, pois eles representam um único esquema conceitual. Ainda que os princípios expressem noções distintas, elas são complementares e indissociáveis aos olhos do pensador persa. Dito de modo mais geral, não é questão, no âmbito da metafísica aviceniana, de modificar os ensinamentos de Aristóteles e estabelecer uma filosofia primeira fundada em novas bases. Se insistimos acerca desse ponto, é porque, após citar o primeiro princípio aviceniano, VERBEKE (1973, p. $37 \star)$ acrescenta:

“A época moderna criou as lógicas plurivalentes. É o caso da Escola polonesa de J. Lukasiewicz e da Escola de Brouwer, partidário da lógica trivalente: o verdadeiro, o falso e o indemonstrável."

Se consideramos essa passagem como uma simples lembrança dos desenvolvimentos modernos da lógica, a afirmação é, sem dúvida, verdadeira, mas pouco instrutiva. Todavia, se a interpretarmos como uma declaração sugerindo, de uma maneira implícita, que os fundamentos da metafísica aviceniana encontram-se ameaçados pelas lógicas plurivalentes, então a afirmação é, por duas razões, filosoficamente discutível. Em primeiro lugar, não nos parece, como sugere as entrelinhas de Verbeke, que a metafísica aviceniana esteja mais exposta aos ataques das lógicas trivalentes do que a aristotélica. Ao contrário, ao escolher Aristóteles como seu interlocutor privilegiado, Lukasiewicz evidencia que, aos seus olhos, é a metafisica aristotélica que seria profundamente abalada em sua estrutura pelas novas lógicas. Em segundo lugar, não somente as lógicas trivalentes são contrárias ao espírito da lógica antiga, mas parece altamente questionável que a versão proposta por Lukasiewicz possa ser vista como uma real alternativa a Aristóteles e Avicena.

Do que foi dito, fica claro que o LPP I, 8 é um capítulo que clama por análises mais minuciosas da parte de seus intérpretes. Diversas questões 
esperam respostas, mas concentraremos nossa atenção sobre aquela que nos parece a mais urgente: Dividiremos nossa análise em cinco partes. A primeira será dedicada a elucidação conceitual do problema que ocupa Avicena quando da determinação do primeiro princípio. A sugestão de Verbeke de propor uma contraposição entre a lógica trivalente de Lukasiewicz e a metafísica antiga é interessante e será adotada para nos auxiliar a melhor compreender os princípios da disciplina suprema. Deixemos, todavia, desde já bastante claro que nosso objetivo não será, de forma alguma, o de analisar as lógicas trivalentes, mas apenas o de realizar algumas observações acerca do percurso intelectual de Lukasiewicz para, com isso, dispormos de alguns conceitos que permitam melhor considerar o significado do texto aviceniano. $\mathrm{Na}$ segunda, trataremos dos primeiros princípios e do modo como eles caracterizam, na lógica aristotélica, as relações lógicas. Na terceira, faremos algumas considerações acerca do vocabulário do pensador persa para oferecer, na quarta parte a formulação do primeiro princípio. Terminaremos com uma análise bastante sumária da dita "prova" aviceniana do primeiro princípio.

\section{0 problema dos princípios}

No início de sua carreira, Jan Lukasiewicz (2000, resumido em 1972) 3 propôs uma interpretação de Gama 4 que colocava em questão as provas fornecidas por Aristóteles. Seu estudo divide-se em duas partes. A primeira é consagrada à reconstrução e à crítica dos argumentos do Estagirita ao passo que a segunda é dedicada à posição do próprio autor sobre o tema. De início, o lógico polonês constata a existência de três formulações do PNC por Aristóteles: ontológica (1005b19-20), lógica (1011b13-14) e psicológica (1005b23-24). Em seguida, observa que o pensador grego busca provar a terceira, mas sem obter sucesso. Quanto às duas primeiras formulações, elas seriam equivalentes e Aristóteles considerá-las-ia como verdadeiras e definitivas, ou seja, não poderiam ser provadas a partir de outras proposições. Ora, Lukasiewicz constesta a afirmação. Para ele, o princípio em questão deve ser demonstrado, como o próprio Filósofo parece reconhecer, já que tenta prová-lo de "modo elêntico ou apagógico". Todavia, uma vez examinadas, as provas oferecidas mostram-se 
errôneas e encontramos mesmo "algumas expressões que testemunham a aflição" de Aristóteles face à fraqueza de seu projeto metafisico.

A análise textual realizada por Lukasiewicz é interessante e certamente merece ser discutida. Não o faremos aqui para não nos desviarmos demais de nosso tema, bastando-nos remeter a CASSIN e NANCY (1989) e as respostas de PUIVET (1999). Ademais, acreditamos ser a segunda parte de seu trabalho mais instrutiva para os nossos propósitos. Grosso modo, o lógico polonês considera que o PNC está fundado em um impasse. Em primeiro lugar, seria razoável exigir-lhe demonstração, mas o exame mostra justamente a impossibilidade de tal prova. O princípio exige demonstração, pois não é verdadeiro por si mesmo, não se tratando do que Lukasiewicz denomina "um princípio definitivo". Além disso, ele não constitui uma lei lógica suprema nem é indispensável para as outras leis lógicas. Ele é distinto dos princípios de identidade e da dupla negação e não pode ser deles inferido. Todavia, ao buscarmos demonstrar o PNC, afirma Lukasiewicz, damo-nos rapidamente conta da impossibilidade de tal prova. O princípio não está baseado em uma evidência direta, pois não é visto como evidente por todos. Também não resulta "nem da negação do juízo falso nem da noção de negação" (LUKASIEWICZ 2000, p. 183). Enfim, e é esse, segundo Lukasiewicz, o ponto mais importante, não é possível demonstrar a inexistência de objetos contraditórios, condição necessária para uma prova do PNC. Não é possível, portanto, oferecer uma prova, pois o princípio "não possui valor" lógico. Lukasiewicz passa então a discorrer sobre os valores práticos e éticos do PNC, uma vez que ele é "a única arma contra o erro e a mentira". Essa seria fundamentalmente a razão pela qual "somos obrigados a admiti-lo" (LUKASIEWICZ 2000, p. 184).

A afirmação segundo a qual o PNC não tem valor lógico pode parecer excessiva, sobretudo se considerarmos sua função nas lógicas clássicas. Talvez Lukasiewicz pretendesse dizer que o princípio não tem um valor absoluto, no sentido de ser absolutamente necessário. Mas ao fim e ao cabo, a posição do autor é filosófica, sendo preferível dizer, para retomar aqui a formulação de POUIVET (1999) que o princípio possui, aos olhos de Lukasiewicz, uma "necessidade antropológica".

Observe-se que Aristóteles está perfeitamente de acordo com Lukasiewicz sobre dizer que o PNC não é demonstrável e, sobretudo, 
que ele não é provado pela lógica. Mais precisamente, para Aristóteles, a necessidade do PNC é, antes de mais nada, de natureza ontológica. Todavia, é precisamente essa tese que Lukasiewicz visa refutar ao evocar a possibilidade de objetos contraditórios. De acordo com o lógico polonês, uma prova do PNC é possível se admitirmos de antemão que "por objeto, é preciso entender unicamente algo que não pode possuir e não possuir uma propriedade” (LUKASIEWICZ 2000, p. 143). Todavia, essa suposição não é justificável, pois não possuímos nenhuma garantia de que os objetos não sejam contraditórios ${ }^{4}$.

Em suma, somos confrontados a duas maneiras de apresentar o PNC. A concepção clássica o entende como um princípio da metafísica e se esforça por justificá-lo como um dos fundamentos do sistema das ciências. A de Lukasiewicz procura, por meio de críticas a Aristóteles, dissociar a validade irrestrita do PNC tanto da ontologia quanto da lógica, confinando-a ao domínio prático. O resultado imediato seria uma maior liberdade que repercutiria diretamente no modo de justificar os princípios lógicos. Aliás, é o próprio LUKASIEWICZ (1970a) que caracteriza seu percurso intelectual como " uma guerra espiritual contra toda forma de coerção que limita o homem”, a pior sendo justamente a coerção em lógica. Somos logicamente livres para conceber outros sistemas nos quais o PNC não é válido, mesmo que eles não tenham nenhum valor para explicar o comportamento humano.

Nos anos trinta, após ter alcançado alguns resultados em lógica proposicional, Lukasiewicz advoga por uma releitura da história da lógica. Seu leitmotiv aparece nas críticas ao famoso historiador alemão C. Prantl: o historiador da lógica deve ter uma sólida formação em lógica matemática ${ }^{5}$ Em 1935, publica em alemão o artigo intitulado Zur Geschichte der Aussagenlogik, no qual sustenta ser a lógica de Aristóteles uma lógica de termos ou de classes, diferente da lógica proposicional estóica. $\mathrm{O}$ artigo alemão era a tradução do próprio autor de um artigo publicado em polonês em 1934 (LUKASIEWICZ 1970c). Mesmo que sua interpretação não seja mais aceita pelos especialistas (vide FREDE 1974 e 1987 e MAROTH 1989, para o estoicismo de Avicena), o artigo teve à época o mérito de modificar profundamente a compreensão do período sem acrescentar nenhum novo texto ao dossiê (MUELLER, 1978). 
Em 1951, aparece $A$ Silogística de Aristóteles, obra cujo objetivo era o de ser simultaneamente uma introdução à lógica formal contemporânea e uma reconstrução da silogística do filósofo grego. Lukasiewicz utiliza um método fundado em duas noções: o princípio de bivalência e as funções de verdade. De início, ele sublinha que o princípio de bivalência deve ser cuidadosamente diferenciado do PTE, formulando a diferença nos seguintes termos:

Esse método (...) funda-se naquilo que se chama "princípio da bivalência”, o qual estabelece que toda proposição é verdadeira ou falsa, ou seja, que dentre os dois valores de verdade possíveis, o verdadeiro e o falso, ela possui um e apenas um. É preciso distinguir esse princípio da lei do terceiro excluído segundo a qual, de duas proposições contraditórias, uma deve necessariamente ser verdadeira e que foi estabelecido como base da lógica pelos estóicos, em particular por Crisipo. (LUKASIEWICZ 1972, p. 97)

No que diz respeito à noção de função de verdade, a ideia é bastante simples:

Todas as funções da teoria da dedução são funções de verdade, ou seja, sua verdade e sua falsidade dependem apenas da verdade ou da falsidade de seus argumentos. (LUKASIEWICZ, 1972, p. 97)

Segundo Lukasiewicz, a noção de valor de verdade é o alicerce de toda a lógica, como ele o formula claramente na sua caracterização da lógica como "the science of logical values" (LUKASIEWICZ, 1970d, p. 90). E ainda que a expressão "princípio de bivalência" seja uma formulação do próprio LUKASIEWICZ (1970c), não somente ele atribui o princípio a Aristóteles, como também o considera essencial para a refutação aristotélica do determinismo. Com efeito, no famoso capítulo 9 do De Intepretatione, Aristóteles teria, em um primeiro momento, sustentado que o PNC, o PTE e o princípio de bivalência implicam o determinismo para, em um segundo momento, atacar essa tese. Assim, buscando fazer face ao determinismo, Aristóteles teria sido forçado a restringir um dos princípios e, ainda segundo Lukasiewicz, a escolha teria recaído justamente sobre a bivalência. Ora, ainda que essa interpretação não seja unânime, o vocabulário por ela introduzido é amplamente aceito e 


\section{8}

desempenha um papel não negligenciável no debate contemporâneo acerca do capítulo 9 (CRAIG, 1988, p. 1-3).

O núcleo da interpretação consiste em dizer que a recusa da bivalência não é plenamente compreensível a não ser que seja introduzido um terceiro valor de verdade: o indeterminado. No entanto, para que seja uma solução válida do problema de Aristóteles, a interpretação deveria satisfazer certas condições. Em primeiro lugar, deveria evidentemente observar o espírito da solução aristotélica. Deveria notadamente ser fiel à ideia aristotélica de indeterminação das proposições contingentes futuras ao mesmo tempo que permitisse invalidar o determinismo. Admitamos, por ora, essa condição como satisfeita ${ }^{6}$. Ademais, a interpretação deveria ainda preservar as noções de base da lógica aristotélica, mas isso a pretensa solução é absolutamente incapaz de fazer. A introdução de um terceiro valor de verdade implica não apenas a recusa da bivalência, mas, no âmbito do modelo proposto, também a do PTE, o que significa o abandono completo da lógica aristotélica e LUKASIEWICZ, (1970e, p. 87-88) mostra-se plenamente consciente desse fato. Mas como devemos compreender, então, essa interpretação? Devemos falar de uma "estranha solução" ou antes de uma maneira retórica de chamar a atenção para o seu próprio programa lógico? Pouco importa. Nosso interesse é de outra ordem. Lukasiewicz forneceunos elementos para a formulação de um problema crucial para a lógica aristotélica e que nos ajudarão na nossa apresentação de Avicena, a saber: como justificar, na lógica aristotélica, as relações lógicas?

Por motivos de clareza, retomemos as linhas gerais do problema:

1. A conjunção do PNC, PTE e PB implica o determinismo;

2. Aristóteles não aceita o determinismo;

3. É necessário renunciar a um dos três princípios e Aristóteles teria escolhido o PB;

4. Segundo Lukasiewicz, a recusa do PB equivale à introdução de um terceiro valor de verdade;

5. Todavia, a introdução de um terceiro valor de verdade implica a recusa do PTE e, com ela, a recusa das bases da lógica e da metafísica antiga;

6. Portanto, ou preservamos a lógica aristotélica e aceitamos o determinismo como uma de suas consequências ou negamos o determinismo e aceitamos as lógicas plurivalentes. 
Duas observações fazem-se aqui necessárias. Em primeiro lugar, como o mostrou URQUHART (1986, p. 72-74 e 110-111), a solução proposta por Lukasiewicz não está livre de problemas. Com efeito, o lógico polonês pensa ser capaz de satisfazer três condições:

i) As funções proposicionais são funções verifuncionais;

ii) $O$ terceiro valor de verdade exprime a noção de possibilidade ou a indeterminação das proposições contingente futuras;

iii) As verdades lógicas são tautologias.

A base do sistema repousa sobre as matrizes para definir a negação e a implicação (LUKASIEWICZ 1970g, p. 166). Seja , portanto, C = implicação, $\mathrm{N}=$ negação, $0=$ falso, $1 / 2=$ possível e $1=$ verdadeiro e seja a seguinte matriz:

\begin{tabular}{l|lll|l}
\hline $\mathrm{C}$ & 0 & $1 / 2$ & 1 & $\mathrm{~N}$ \\
\hline 0 & 1 & 1 & 1 & 1 \\
$1 / 2$ & $1 / 2$ & 1 & 1 & $1 / 2$ \\
1 & 0 & $1 / 2$ & 1 & 0 \\
\hline
\end{tabular}

Consideremos a situação C 1/2 1/2: de acordo com as condições i) e ii), seu valor deveria ser $1 / 2$. Todavia, Lukasiewicz escolheu 1 . Por quê? Porque ele queria preservar a condição iii). Com efeito, se C 1/2 1/2 =1/2, então Cpp não seria uma tautologia. Assim, essa maneira de introduzir um terceiro valor de verdade repousa em um dilema: ou se preserva i) e ii) sustentando que C $1 / 21 / 2=1 / 2$ ou se mantém iii) afirmando que $C$ $1 / 21 / 2=1$. Em todo caso, as três condições não podem ser simultaneamente satisfeitas.

Em segundo lugar, perguntemos como os antigos poderiam negar 4 sem incorrer na introdução de um terceiro valor de verdade. Ou, inversamente, por que a recusa de 4 pareceria implicar a introdução de um terceiro valor de verdade? A razão parece simples: como explicar as relações lógicas independentemente da bivalência? Seja $\mathrm{P}$ a proposição "há uma batalha naval" e marquemos os diferentes aspectos temporais de seu verbo pelos índices $\mathrm{t}_{0}<\mathrm{t}<\mathrm{t} 1$ (respectivamente, "houve", "há" e "haverá"), recusar a bivalência é dizer que:

a) $P_{\text {to }}$ é verdadeira ou falsa;

b) $\mathrm{P}_{t}$ é verdadeira ou falsa; 
c) $P_{t 1}$ não é nem verdadeira nem falsa.

Por óbvio, as seguintes proposições são verdadeiras:

i) $\left(\mathrm{P}_{\text {to }} \mathrm{v} \sim \mathrm{P}_{\text {to }}\right) ; \sim\left(\mathrm{P}_{\text {to }} \wedge \sim \mathrm{P}_{\text {to }}\right)$;

ii) $\left(\mathrm{P}_{\mathrm{t}} \mathrm{v} \sim \mathrm{P}_{\mathrm{t}}\right) ; \sim\left(\mathrm{P}_{\mathrm{t}} \wedge \sim \mathrm{P}_{\mathrm{t}}\right)$;

Mas como explicar as relações lógicas entre:

iii) $\left(\mathrm{P}_{\mathrm{t} 1} \mathrm{v} \sim \mathrm{P}_{\mathrm{t} 1}\right) ; \sim\left(\mathrm{P}_{\mathrm{t} 1} \wedge \sim \mathrm{P}_{\mathrm{t} 1}\right)$;

É nesse momento que a decisão de Lukasiewicz de interpretar as relações lógicas como funções de verdade se mostra em toda sua força. As proposições presentes em $\mathrm{i}$ e ii são verdadeiras porque $\mathrm{P}_{\text {to }}$ e $\mathrm{P}_{\mathrm{t}}$ possuem valores de verdade determinados. Mas como explicar que $\left(\mathrm{P}_{\mathrm{t} 1}\right.$ $\left.\wedge \sim \mathrm{P}_{\mathrm{t} 1}\right)$ é uma contradição se $\mathrm{P}_{\mathrm{t} 1}$ não tem valor de verdade? Como explicar então as relações lógicas introduzidas pela negação e pelos demais conectivos? Ora, Aristóteles disse que $\mathrm{P}_{\mathrm{t} 1}$ não tem valor de verdade determinado e Lukasiewicz fez do indeterminado um valor de verdade $^{7}$. Ele pensava assim ser capaz de salvar as relações lógicas entre as proposições e manter a explicação dos conetivos como funções de verdade, mas é discutível que ele tenha alcançado êxito. A estratégia adotada por Lukasiewicz não é aristotélica, mas ela nos ensina muito sobre a lógica antiga. Sobretudo, deixa claro um ponto que deveria ser óbvio: Aristóteles não interpretava a negação e os demais conetivos como funções de verdade. Resta-nos então explicar como ele os interpretava. Mesmo que não adotemos a solução de lógico polonês, o seu problema continua: como Aristóteles e, no nosso caso, Avicena interpretavam as relações lógicas? E como eles podem pretender mantê-las sem apelar para as noções de verdade e falsidade?

Os dois momentos da pesquisa de Lukasiewicz a que fizemos alusão, as críticas ao PNC e o abandono do PTE, podem ser vistos como apontando para um único problema. O segundo, mais amplo que o primeiro, atesta a radicalização da problemática. Não se trata de provar, por exemplo, que $\sim(p \wedge \sim p)$ e $(p \vee \sim p)$ são tautologias, algo que Lukasiewicz sustenta ser fácil de fazer na lógica contemporânea (LUKASIEWICZ, 1970e, p. 105). O problema é outro. A dificuldade consiste em identificar os pressupostos da lógica e a maneira de defendê-los. Ora, é nesse 
momento que Lukasiewicz se nos revela instrutivo. Com efeito, ele reconhece explicitamente que:

Porque ele reside nos fundamentos da lógica, o princípio em discussão [sc. o PB] não pode ser provado. Pode-se apenas acreditar nele, mas apenas quem o considera evidente acredita. Pessoalmente, estou autorizado a não reconhecê-lo e a aceitar a ideia de que além da verdade e da falsidade existem outros valores de verdade, incluindo ao menos um outro, o terceiro valor. (LUKASIEWICZ, 1970b) ${ }^{8}$

Para o lógico polonês, não há problema algum no fato do $\mathrm{PB}$ não poder ser justificado. As dificuldades nascem para quem sustenta que se trata de um princípio necessário para a lógica, ou seja, para quem procura negar que há outros princípios capazes de desempenhar a mesma função. De fato, o PB não é justificável pela mesma razão pela qual ele não é o único princípio possível, ou seja, pela noção de função de verdade. Se as relações lógicas são concebidas como verifuncionais, então a definição dos funtores depende apenas dos valores lógicos de seus componentes. Mas não seria problema da lógica demonstrar que os componentes admitem apenas dois valores ou se admitem mais de dois.

Está claro, portanto, que Lukasiewicz considera a noção de função de verdade muito mais central do que a de bivalência. Além disso, não estando presente nem em Aristóteles nem em Avicena, a noção de função de verdade parece ser o divisor de águas das duas teorias. Quando o filósofo grego e o persa aceitam a validade absoluta do PNC e do PTE ao mesmo tempo que negam a do PB, eles estão aceitando que os dois princípios podem ser defendidos independentemente das noções de verdade e falsidade. Logo, se essas noções forem resultantes da defesa dos dois princípios, e não supostas por ela, então os dois pensadores podem reivindicar ter razões para defender a existência de apenas dois valores de verdade. Mas quer isso dizer que a solução aristotélica e aviceniana do problema dos futuros contingentes decorra do modo como eles argumentam em favor do PNC e do PTE, respectivamente, em Gama e no LPP I, 8? É o que nos parece. Todavia, antes de explorarmos essa via, precisaremos fazer algumas observações acerca das relações entre os princípios. 


\section{As relações entre o PNC e o PTE}

De início, lembremos que Aristóteles e Avicena não utilizam as expressões "princípio de não contradição", "princípio do terceiro excluído" ou "princípio de bivalência". O primeiro a fornecer uma formulação informal do PNC parece ter sido Platão (República IV, 436b) e, ainda que Aristóteles tenha empregado expressões bastante próximas, o primeiro a chamá-lo por um nome técnico foi Alexandre de Afrodísias ao empregar a expressão "axioma tes antitaseis". Trata-se, portanto, de uma nomenclatura posterior que visa fazer justiça a noções empregadas por filósofos e lógicos antigos e especialmente por Aristóteles quando esse afirma:

Chamo princípios da demonstração as opiniões comuns que servem de base a toda demonstração, tais como: "tudo deve ser necessariamente afirmado ou negado" e "é impossível que uma coisa seja e não seja ao mesmo tempo". (996b28)

Ademais, se considerarmos o uso que o Estagirita faz dessas noções, veremos que ele tinha plena consciência das consequências de cada princípio. Com efeito, em Gama 5 e 6, ele funda suas críticas a Protágoras na impossibilidade da afirmação e da negação serem simultaneamente verdadeiras ao passo que, em Gama 7, ele critica Anaxágoras ao demonstrar que as duas proposições não podem ser simultaneamente falsas. Ainda assim, dizer que Aristóteles admite as relações lógicas expressas pelos princípios não equivale a dizer que a interpretação de sua lógica em termos de funções de verdade expresse bem a sua compreensão das relações lógicas. Isso é particularmente evidente no caso da recusa expressa de que a defesa do PNC possa ser feita supondo-se a relação de oposição entre verdade e falsidade:

Além disso, se, quando uma proposição é verdadeira, a negação é falsa e se, quando a negação é verdadeira, a afirmação é falsa, então não será possível que a mesma coisa seja, ao mesmo tempo, afirmada e negada com verdade. Mas poder-se-á dizer que se comete aí petição de princípio. (1008a34)

A acusação de petitio principii não deixa dúvida que os argumentos em favor do primeiro princípio não podem supor a verdade ou a falsidade 
das proposições. Bem ao contrário, deve ser possível demonstrar, na base do PNC e do PTE, que uma proposição possui apenas um de dois valores de verdade que se excluem mutuamente. Encontramos um segundo indício no argumento proposto no capítulo 6 do De Interpretatione, onde Aristóteles julga estar demonstrando que a caracterização de uma proposição como verdadeira ou falsa supõe a caracterização da proposição como uma atividade enunciativa. Após ter estabelecido que uma proposição é "uma emissão de voz possuindo um significado que diz respeito à presença ou ausência de um atributo em um sujeito" (17a22), o Estagirita passa a retirar algumas consequências dessa tese. É preciso salientar aqui o papel desempenhado pela nítida separação entre o nível do discurso humano enunciativo e o da realidade. A proposição, entendida como uma atividade humana, notadamente a de comunicação, é uma atividade complexa, pois resulta da combinação de, ao menos, duas operações ou funções exercidas por nomes segundo certas regras sintáticas e semânticas próprias a cada língua: a de identificação de algo de que se fala (o sujeito de atributos) e a caracterização ou atribuição de algo àquilo de que se fala. Assim, no nível do discurso, existem duas possibilidades que correspondem a duas formas de proposição: a) a combinação de nomes enuncia a presença do atribuído no sujeito de que se fala, caso da proposição afirmativa; b) a combinação de nomes enuncia a ausência do atributo no sujeito, caso da proposição negativa. No nível ontológico, há igualmente duas possibilidades: a') a real presença de um atributo no sujeito; b') a ausência de um atributo no sujeito. Note-se que seria nesse momento que ganharia força a afirmação de Lukasiewicz segundo a qual haveria a suposição de que os objetos não são contraditórios. Contra isso, diga-se que o De Interpretatione seria uma obra lógica que apenas explora logicamente algo que deveria ser evidenciado pela metafisica. Deixando de lado por ora esse problema, podemos chamar a atenção para duas características do modelo proposto no De Interpretatione: i) a possibilidade da relação entre os dois níveis; ii) sua independência. A primeira característica diz respeito à natureza da proposição como uma atividade significativa. Aristóteles e Avicena concebem a proposição como um complexo cuja significação é tributária de suas partes (os nomes, no vocabulário de Aristóteles) e entendem a significação dos nomes em função daquilo que eles simbolizam. Como o que os nomes simbolizam 


\section{4}

é um sujeito de atributos ou um atributo do sujeito, segue-se que a significação da proposição é a afirmação (ou negação) da presença (ou ausência) de um atributo em um sujeito. A segunda característica informa-nos que não há correspondência necessária entre a afirmação da presença de um atributo em um sujeito e a real existência dessa relação. Em outros termos, ainda que a significação da proposição seja a representação de um vínculo (presença ou ausência) real entre o sujeito e o atributo, a significação é independente da existência do vínculo. O Estagirita deixa claro esse ponto ao afirmar que a relação entre os dois níveis configura quatro possibilidades:

Pois que é possível afirmar o que pertence a uma coisa como não lhe pertencendo, o que não the pertence como the pertencendo, o que the pertence como pertencendo, o não lhe pertence como não lhe pertencendo, e isso segundo o tempo e não apenas no momento presente, então deve ser possível negar tudo o que foi afirmado e afirmar tudo o que foi negado. (17a26)

Convém aqui assinalar que as traduções latinas de Avicena ensinavam precisamente a mesma lição, como constatamos sob a pena de ALBERTO MAGNO 1890, p. 411a:

Com efeito, Avicena diz que essas quatro se dividem do seguinte modo: pois é possível, na enunciação afirmativa, enunciar ser o que é. É possível enunciar, na sua negativa, não ser o que é. É possível enunciar ser o que não é, por meio da afirmação da negação oposta. E é possível enunciar não ser o que não é, pela negação da negação oposta.

Há, portanto, quatro possibilidades. Mas se acrescentarmos a esse esquema a definição aristotélica de verdade, segundo a qual: "dizer do ser que ele não é ou do não-ser que ele é, é dizer o falso; dizer do ser que ele é ou do não-ser que ele não-é, é dizer o verdadeiro" (1011b26), então duas das possibilidades serão verdadeiras e duas falsas, pois a proposição será verdadeira ou falsa, conforme o vínculo que ela apresenta existir ou não. Assim, de um lado, é constitutivo da atividade enunciativa que ela represente um certo arranjo entre a coisa de que se fala e um atributo e isso independentemente da existência ou não do arranjo e independentemente da verdade ou da falsidade. Aristóteles buscava, portanto, apresen- 
tar a relação de oposição entre uma afirmação e sua negação como decorrente da própria atividade enunciativa. Faz parte da natureza da atividade enunciativa a escolha, pelo sujeito que realiza a atividade, entre uma das duas possibilidades exclusivas e exaustivas: a enunciação da presença ou da ausência de um atributo em um sujeito. Não escolher uma das duas possibilidades equivale simplesmente a não realizar a atividade. Ora, se os dois modos de significação são, de fato, exclusivos e exaustivos, então, basta acrescentar a noção de verdade e de falsidade para obter as chamadas formulações lógicas dos princípios:

PNC $=$ duas proposições, uma a negação da outra, não são verdadeiras ao mesmo tempo;

PTE $=$ duas proposições, uma a negação da outra, não são falsas ao mesmo tempo.

Não é dificil perceber que a conjunção dessas duas formulações acarreta o PB (KNEALE e KNEALE 1984, p. 47, possuem, todavia, uma interpretação mais forte). Mas isso não autoriza a concluir a validade irrestrita do $\mathrm{PB}$, pois o conceito de verdade empregado é modalizado temporalmente (BARBOSA FILHO 2004, p. 233-34). Ainda que o nível da atividade enunciativa seja independente do ontológico, a noção de verdade introduzida supõe a prioridade do nível ontológico, pois é porque as coisas são de tal modo que a proposição será dita, conforme o caso, verdadeira ou falsa. Se a existência das coisas é condição da verdade das proposições e se o nível ontológico é constituído por coisas em mudança e, portanto, no tempo, então a temporalidade marcará a relação entre os dois níveis, estando presente, portanto, na noção de verdade. Ou seja, como os enunciados futuros contingentes dizem respeito a coisas não existentes, então as condições de verdade desses enunciados ainda não estão satisfeitas, não sendo esses enunciados verdadeiros ou falsos. Não se trata, portanto, de recusar o $\mathrm{PB}$, mas apenas de restringi-lo ou, melhor ainda, de enfatizar seu aspecto temporal, uma vez que o princípio é formulado por meio da noção de verdade que é uma noção temporalmente modalizada.

Dizer, por conseguinte, que o PTE e o PNC são válidos independentemente do $\mathrm{PB}$ equivale a dizer que esse princípio é temporalmente modalizado ao passo que aqueles não. Mas se isso é assim, cabe explicar 
melhor como o PNC e o PTE pode ser válidos para proposições contingentes futuras. As linhas gerais da resposta já devem estar claras: a oposição entre as proposições que será usada na formulação dos princípios não depende da verdade das proposições, mas da natureza da atividade significativa. Duas proposições, uma a negação da outra, são opostas de modo exclusivo e exaustivo em virtude da significação e não da verdade ou falsidade. A significação da proposição afirmativa é a enunciação da presença do atributo no sujeito. A significação da proposição negativa é a enunciação da ausência de atributo no sujeito. Em ambos os casos, isso é feito independentemente da existência da relação descrita. Sendo assim, a dupla possibilidade impõe-se sempre que se queira realizar a atividade enunciativa. Mas por quê? Por que não seria possível enunciar simultaneamente a presença e a ausência de um atributo no sujeito. Essa pergunta leva-nos a ler a refutação daquele que nega o primeiro princípio.

\section{3) 0 primeiro princípio}

A caracterização por Avicena dos princípios e das noções primitivas da metafísica não está isenta de dificuldades. Nessa seção, analisaremos apenas uma ambiguidade ligada à determinação da natureza do primeiro princípio. Com efeito, trata-se de um princípio da metafísica ou da teoria demonstração? Como encontramos ambas as afirmações, o primeiro passo consiste em clarificar em que sentido as duas afirmações são possíveis.

Por um lado, a expressão "primeiro princípio da metafísica" poderia ser entendida como fazendo referência à premissa mais fundamental na série argumentativa. Ora, o conjunto do conhecimento humano é caracterizado por Avicena como estruturado em disciplinas hierarquicamente distintas de tal modo que uma ciência C é superior a outra C' se os princípios não evidentes de C', portanto aqueles que exigem provas, são demonstrados em C. Sendo a metafísica a ciência que ocupa o topo hierárquico do sistema, caberia a ela provar os princípios da matemática e da fisica. Todavia, a caracterização da metafísica como uma ciência implica que ela própria deva partir de princípios. O primeiro princípio da metafisica seria, nessa acepção, aquele a partir do qual seriam provados 
os princípios das demais disciplinas o que implicaria dizer que o primeiro princípio funciona como premissa no argumento mais primitivo realizado no interior da metafisica. Por outro lado, a caracterização do primeiro princípio como princípio da demonstração sugere que ele seja admitido em toda argumentação, seja ela metafísica, matemática ou fisica.

A maneira talvez a mais simples de tornar as duas afirmações compatíveis consistiria em sustentar que o primeiro princípio desempenha o papel de premissa em todo argumento. Todavia, essa estratégia está excluída de antemão, pois, como ensinava já Aristóteles:

Que não é possível afirmar e negar ao mesmo tempo é algo que não é posto por nenhuma demonstração, a menos que a conclusão a ser provada tenha também essa forma. (77a10-12)

Aristóteles fala aqui do PNC, mas algo similar vale para o PTE (LEAR 1980, p. 101-102):

Que tudo seja afirmado ou negado verdadeiramente é algo suposto pela demonstração que procede por redução ao absurdo. (77a20)

Em outras palavras, o primeiro princípio da metafisica, seja ele o PNC ou o PTE, não deve ser considerado como sendo, segundo a divisão clássica dos Segundos Analíticos, uma tese, mas sim um axioma, ou seja, como algo presente em toda argumentação, ainda que não operando como premissa do silogismo científico. Se pensarmos na noção clássica de argumento como um raciocínio que, como insiste AVICENA (1508, fo 2ra), conduz de algo a algo, ou seja, se o bom argumento se caracteriza por ser um mecanismo de preservação da verdade das premissas para a conclusão, de tal modo que, se partimos de algo verdadeiro, chegaremos a algo verdadeiro, então a função do primeiro princípio fica mais clara. Com efeito, a razão para, aceita as premissas, aceitar-se a conclusão parece ser precisamente que quem aceita as premissas e nega a conclusão recai em contradição. Isso fica claro no método antigo para selecionar as boas formas silogísticas: o contra-exemplo. Se um argumento é bom em virtude de sua forma (ou válido, como diríamos hoje), então não pode ser possível construir um novo argumento com a mesma forma, com premissas verdadeiras e conclusão falsa. Sendo assim, a despeito da pluralidade de formas selecionadas por esse método e listadas nas obras lógicas, 


\section{8}

há um princípio comum a toda demonstração, pois todo bom argumento parece supor que a afirmação conjunta da verdade das premissas e da falsidade da conclusão é uma contradição.

Mas esse modo de proceder não conduziria a fazer do primeiro princípio um princípio da lógica e não da metafísica? Ao contrário, Avicena insiste sobre o fato de uma disciplina não poder estabelecer os seus princípios. A lógica é a disciplina encarregada de estabelecer as boas formas de argumentação, apresentando os tipos possíveis de premissas e as formas sologísticas corretas. Para realizar essa tarefa, ela supõe que o argumento correto é aquele que preserva a verdade das premissas para a conclusão. Supõe, portanto, que o bom argumento não pode ter premissas verdadeiras e conclusão falsa. Mas como responder aquele que se obstina a dizer não haver problemas em aceitar-se simultaneamente a verdade das premissas e recusar-se a da conclusão? A lógica e qualquer outra das disciplinas matemáticas e físicas não teriam nada a responder, justamente porque elas supõem a verdade do princípio sem o qual não há argumentação possível. Quem o nega, está negando a possibilidade mesma da racionalidade, entendida como capacidade de argumentar. Se não fosse possível, partindo de algo verdadeiro, concluir algo verdadeiro, então toda verdade seria obtida apenas pelos sentidos e não seríamos mais do que animais. (Ou talvez menos, dado o famoso exemplo de Avicena da ovelha que foge ao ver o lobo). A racionalidade humana está, aos olhos de Avicena, ligada à capacidade de argumentar. Mas não cabe a lógica realizar a defesa da racionalidade humana. Caberia a quem? Para Avicena, somente a disciplina que investiga os primeiros princípios do conhecimento e do ser poderia pronunciar-se sobre isso.

Chegamos, assim, à primeira parte da resposta: o princípio supremo de toda argumentação deve pertencer à metafísica, pois ela é a disciplina suprema. Por óbvio, não temos aqui um teorema da metafisica, ou seja de algo demonstrado no interior dessa ciência e suposto pelas demais, pois sendo princípio de toda argumentação, é suposto mesmo pelas provas metafísicas. Além disso, por pertencer à metafisica, o princípio versa sobre o ser enquanto ser. Ora, Avicena distingue dois tipos de princípios: aqueles que tratam de um gênero particular e aqueles comuns a todos os gêneros e que, segundo ARISTÓTELES (77a26), desempenham um papel de base em toda demonstração. Tem-se assim uma distinção acerca do uso que faze- 
mos dos princípios (não uma classificação segundo gêneros) que precisa ser considerada no âmbito da discussão acerca da proibição de metabasis (75a37, vide LIVESEY, 1989). Sejam os seguintes princípios9:

i) Acerca de todo atributo, sua afirmação ou negação a algo é verdadeira;

ii) Duas coisas quaisquer, elas são iguais ou desiguais;

iii) Duas grandezas quaisquer, elas são iguais ou desiguais.

Os três princípios podem ser vistos de uma dupla perspectiva: ou como princípios distintos pertencentes a ciências distintas, ou como um único princípio formulado de modo específico de acordo com o gênero próprio investigado por cada disciplina. Nesse último caso, o adotado por Avicena, ii e iii seriam meras especificações de $i^{10}$. No âmbito da sua filosofia, o mecanismo que permite esse procedimento de especificação é, de um lado, a relação hierárquica entre os gêneros e as espécies e, de outro, a noção de ser como suprema e ligada a todas as categorias secundum prius et posterius, ou seja, primeiramente à substância e posteriormente às demais categorias ( $L P P$, p. 4046-48). Sendo assim, a metafísica, enquanto disciplina suprema, deve ter por princípios as proposições que descrevem o ser do modo o mais geral, enunciando as propriedades necessárias de todos os seres. Portanto, o PNC e o PTE são princípios na medida em que descrevem o ser enquanto ser. Por tratarem do ser, versam sobre aquilo que é considerado em todo discurso possível, pois todo discurso enunciativo deve ser acerca de algo. Por descreverem o ser de modo adequado e colocando em evidência suas propriedades necessárias e gerais, satisfazem as condições para serem proposições científicas, ou seja, são verdadeiras, universais e necessárias. Poderíamos dizer que encontramos na disciplina metafísica um certo ponto de convergência entre a lógica, a ontologia e a epistemologia por meio dos princípios supremos, havendo, no entanto, aos olhos de Avicena e de Aristóteles, uma primazia da ontologia. Ademais, o vínculo entre o problema dos futuros contingentes e a discussão acerca do primeiro princípio da metafísica torna-se um pouco mais claro. A proposição "amanhã haverá um batalha naval ou amanhã não haverá uma batalha naval" pode ser dita verdadeira por especificação de uma caracterização geral acerca do ser enquanto ser e sem que precisemos aceitar que um dos membros da 
disjunção, tomado isoladamente, seja verdadeiro. Cada disjunto apresenta apenas uma possibilidade do ser. Tomados em conjunto, representam o conjunto completo de possibilidades, sendo, portanto, um caso do princípio que descreve as propriedades gerais do ser. Como o princípio é verdadeiro, suas especificações também o são.

\section{Observações terminológicas}

Podemos agora voltar ao nosso problema inicial e perguntar em que medida Avicena se afasta de Aristóteles ao formular o primeiro princípio da metafísica. Devemos iniciar perguntando se a afirmação de Verbeke segundo a qual o pensador persa "adota como primeiro princípio o do terceiro excluído" é correta e, caso o seja, se isso significa uma verdadeira ruptura com a filosofia do Estagirita. Acreditamos que o texto não autoriza essa conclusão e proporemos uma leitura alternativa. Para tanto, apresentaremos na presente seção algumas observações terminológicas visando a explicar o modo de expressão escolhido por Avicena. Por fim, forneceremos, na última seção, uma análise bastante breve dos principais passos da argumentação aviceniana.

Se nos limitarmos a considerar a letra do texto, a tese avançada por Verbeke parece irrepreensível, pois parece realmente que os dois filósofos enunciam princípios distintos. Em sua Metafísica, Aristóteles escreve:

Evidentemente, um tal princípio é o mais certo de todos; podemos agora enunciar qual é esse princípio. Ele diz que o mesmo atributo não pode pertencer e não pertencer ao mesmo sujeito e sob o mesmo aspecto, sem prejuízo de outras determinações que poderiam ser acrescentadas para escapar as dificuldades dialéticas. (1005b15-19)

Avicena, por sua vez, parece formular algo mais próximo do PTE, ao dizer:

A primeira dentre todas as enunciações mais certas e à qual se relacionam todas as demais por análise (...) é que entre a afirmação e a negação não existe intermediário. E essa propriedade não é um acidente de nenhuma coisa, mas um acidente do ser enquanto possui ser e enquanto comum a tudo que é. ( $L P P$ p. $56^{70-74}$ ) 
Texto a ser comparado com Aristóteles:

Mas, de outro lado, não pode existir intermediário entre os contraditórios, mas, acerca de um sujeito, deve-se afirmar ou negar um predicado qualquer. (1011b23)

Essa aparente preferência aviceniana pelo PTE parece-nos, contudo, não tão evidente quanto Verbeke proclama. Com efeito, não nos parece necessário dever interpretar a formulação acima como a enunciação do PTE em detrimento do PNC. Caso considerarmos a sequência argumentativa do texto aviceniano, encontraremos elementos para perceber, e isso talvez mesmo mais nitidamente que em Aristóteles, que os dois princípios devem ser tomados como descrevendo uma única estrutura conceitual cuja descrição seria a seguinte: dadas duas proposições opostas de uma certa maneira, que chamaremos contraditória, elas descrevem o ser de modo simultaneamente exclusivo e exaustivo. É precisamente essa estrutura que Avicena procura defender e veremos que seu primeiro princípio é a formulação dessa oposição.

Preliminarmente à determinação do primeiro princípio, Avicena propõe distinguir as ordens do real e do discurso, distinção que ele elabora por meio de um duplo uso da noção de verdade. Em um primeiro sentido, pode-se dizer que as coisas são verdadeiras, entendendo "verdade" como sinônimo de "existência". Assim, dado que os objetos existentes no mundo estão em relações causais, é possível formular uma escala da verdade em função do modo de existir dos objetos, de tal sorte que o que existe por si e, portanto, de modo necessário é chamado "aquilo que é sempre verdadeiro" ou "o verdadeiro por si". Por outro lado, aquilo cuja existência é causada por um outro é dito ter sua verdade tributária ou dependente, sendo, em si, falso (LPP p. 5561-63). Em um segundo sentido, são as proposições que são ditas verdadeiras e isso na exata medida em que existe uma adequação entre a proposição e aquilo que ela descreve ( $L P P$ p. $55^{64-5667}$ ). A distinção é bastante simples, mas possui consequências importantes, notadamente no que pode ser considerado como o mais verdadeiro nas duas ordens. Em outros termos, a admissão da adequação à realidade como critério de verdade das enunciações não implica que a ordem real e a ordem da verdade das proposições sejam equivalentes. A proposição mais verdadeira não é aquela que afirma a 
existência de Deus, ser mais verdadeiro. Podemos assim concluir que, em certo sentido, o fundamento último do conhecimento para Avicena não é nem a existência de Deus nem a iluminação mística. Malgrado a importância do dator formarum para a aquisição das essências, a ordem de justificação do conhecimento possui seu fundamento, em última instância, no primeiro princípio de todas as demonstrações, principal fundamento do sistema do conhecimento humano. A insistência na ordem da justificação permite a Avicena formular o princípio em termos proposicionais (inter affirmationem et negationem non est medium) e colocar em evidência que se trata de uma certa oposição entre as enunciações.

Notemos, além disso, que o uso desse modo de expressão não implica que Avicena esteja conscientemente afastando-se de Aristóteles. Com efeito, encontramos já nos escritos do Estagirita formulações semelhantes a de Avicena e em lugares em que sua intenção era expressamente a de caracterizar a oposição entre as proposições. Eis dois exemplos:

Agora, se os tipos de oposição são a contradição, a privação, a contrariedade e a relação e se destas a primeira é a contradição e a contradição não admite intermediário, ao passo que os contrários admitem um, então é claro que a contradição e a contrariedade não são idênticas. (1055 b 1-4. Grifos nossos.)

Uma enunciação é qualquer uma das partes de uma contradição. Uma contradição é uma oposição que não admite intermediário. (72a11. Grifos nossos.)

Por óbvio, uma oposição é dita ter um intermediário se o objeto em questão pode possuir uma propriedade cuja atribuição torna falsas as duas enunciações opostas. E dado que a oposição contraditória não possui intermediário, então, admitindo-se a definição de verdade, podemos concluir que:

Entre as oposições, a contradição não admite meio termo, pois a contradição é uma oposição na qual um ou outro dos lados deve estar ligado a um sujeito qualquer, isto é, sem nenhum intermediário. (1057a32-35)

Aristóteles ensina-nos, portanto, que ainda que a contradição seja uma oposição entre uma afirmação e uma negação (17a32), não se trata da única oposição possível. Ela é aquela que, se a afirmação é verdadeira, a 
conclusão é falsa e se a afirmação é falsa, a negação é verdadeira, não podendo ser confundida com os demais tipos de oposição. Ora, encontramos exatamente a mesma lição em Avicena, notadamente em sua célebre passagem acerca do estatuto das essências:

Se alguém nos interrogasse acerca da equinidade segundo a

contradição, a saber, se a equinidade, enquanto equinidade, é $a$ ou não

$\langle a\rangle$, não haveria uma resposta a não ser de acordo com a negação.

(LPP, p. $22943-45)$

Evidentemente, a expressão "interrogar segundo a contradição" não significa "interrogar segundo o princípio de não contradição", mas "segundo a negação contraditória". A intenção de Avicena não é a de suspender o PNC, afirmando que ele não se aplica ao caso em exame. Busca apenas provar que a aludida oposição não é exaustiva, pois é possível negar ambos os predicados opostos.

O conjunto de passagens acima citadas parece levantar dúvidas acerca do caráter peremptório da afirmação de Verbeke, pois não seria totalmente desprovido de plausibilidade não ler a formulação de Avicena como a expressão estrita da PTE. Parece possível que o filósofo persa, em perfeita harmonia com uma prática que se encontra já em Aristóteles, tivesse adotado uma certa maneira de exprimir a oposição contraditória: ela é primitiva em relação aos demais tipos de oposição e, por isso mesmo, o fundamento para explicar as relações lógicas entre as proposições. Além disso, se analisarmos o movimento argumentativo do texto aviceniano, constataremos que os dois princípios (PNC e PTE) são sucessivamente enunciados e defendidos. Consideramos isso um bom indício para sustentar que os dois princípios estavam indissociavelmente ligados na concepção que Avicena se fazia da metafísica. Ora, negar os princípios equivaleria a negar que uma proposição e sua negação opõemse contraditoriamente. E é precisamente o que faz o sofista, aquele que "não entende os extremos das contraditórias" ou "não entende as suas disposições e condições” ( $\left.L P P, \mathrm{p} \mathrm{56^{78-79 }}\right)$.

\section{A defesa aviceniana do primeiro princípio}




\section{4}

Passemos agora a uma rápida análise da "demonstração" aviceniana, sem, contudo, reconstruir passa a passo sua defesa, mas limitando-nos a alguns pontos relevantes para o nosso tema. Ora, tanto para Aristóteles quanto para Avicena, a especificidade do primeiro princípio obriga a adotar uma estratégia peculiar para refutar quem obstinadamente nega sua validade. $\mathrm{O}$ argumento apresentado não pode ter nem a forma silogística nem a de uma redução ao absurdo. (LEAR, 1980, p. 100, resume bem o ponto já bastante debatido na literatura). Em ARISTÓTELES (1006a15), o argumento é dito ser uma prova por refutação ou retorção (BOLTON 1994). Já Avicena serve-se daquilo que a tradução latina medieval chama uma "argumentatio secundum comparationem" (LPP, p. 584-5), ou seja, de um argumento no qual se o adversário concede certas coisas, então a conclusão segue-se. O argumento possui a forma de um diálogo no qual quem exige a justificação ou, como diz Avicena, quem solicita ser guiado (em latim, o imbecillis) começa dizendo algo. É importante que o argumento seja um diálogo, pois a estratégia consiste fundamentalmente em fazer o adversário compreender que se ele deseja falar, então deve aceitar o princípio em questão. De início, o adversário deve admitir que, ao falar, emprega proposições que são significativas tanto para ele quanto para o seu interlocutor. A determinação do significado do discurso aparece, então, como condição mínima da própria existência do debate $\left(L P P\right.$, p. $\left.59^{36-37}\right)$. Aquele que pretender negar o princípio, deverá, também e antes de mais nada, negar que seu discurso: a) não tem significação alguma; b) significa ao mesmo tempo todas as coisas (LPP, p. 5937 $60^{42}$ ), pois ambas as possibilidades tornam o discurso vácuo sem, portanto, precisar ser refutado.

Insistamos no fato de que a obrigação de negar a) e b) não se impõe como resultado de uma reductio ad absurdum, uma vez que esse tipo de estratégia cometeria uma petição de princípio. $\mathrm{Na}$ reductio, pretende-se que a dedução de uma contradição acarreta o abandono da proposição adotada como ponto de partida. Ora, no caso em questão, não se trata de deduzir uma contradição, mas simplesmente de evidenciar a relação de suposição existente entre a realização de uma atividade e suas condições de execução. Para que seja possível dizer que uma atividade foi exercida, as condições que a tornam possível devem ter sido satisfeitas. Caso o sofista recuse-se a aceitar essas condições, ele é condenado a não poder 
enunciar uma proposição significativa, ou seja, a não ter realizado a atividade que torna possível o diálogo. Sendo assim, ele não pode nem ao menos pretender colocar em dúvida o primeiro princípio. Avicena resume bem esse ponto ao afirmar:

E isso é surpreendente: o sofista, cuja intenção é a de exigir explicações, é necessariamente conduzido a uma de duas coisas, a saber, ou cessa [de exigir] e silencia, ou reconhece sem dúvida que se alcançou, a apartir dessas coisas, uma conclusão contra ele ( $L P P$, p. $\left.58^{5-8}\right)$.

O sofista exerce uma atividade enunciativa apenas quando ele profere uma proposição possuindo significação, ou, como diz Avicena, quando ele significa algo ou diversas coisas determinadas (aliquid vel aliqua multa determinata). Convém acentuar esse aspecto: significar uma coisa determinada não equivale a significar um único objeto, mas a utilizar noções determinadas de um modo unívoco. A existência da equivocidade (nomen commune, na tradução latina) não constitui uma verdadeira dificuldade, pois é sempre possível sua eliminação mediante o uso de noções não equívocas ( $L P P$, p. 6045-49). A sequência do argumento é estruturada em duas partes. A primeira estabelece que "a afirmação e a negação não se unem conjuntamente em algo nem são simultaneamente verdadeiras (LPP, p. 62 $2^{75-77}$ ), ao passo que a segunda mostra, de modo estruturalmente semelhante, que a afirmação e a negação "não são simultaneamente separadas de algo nem são simultaneamente falsas" (LPP, p. 6277-82). Ora, se, de fato, é essa a sequência argumentativa adotada, então podemos concluir que o texto aviceniano segue a mesma sequência do aristotélico, ou seja, primeiramente analisa o PNC e, posteriormente, o PTE, não havendo, quanto a isso, ruptura com o modelo do Estagirita.

A defesa de que dois predicados opostos (v.g., homo e non-homo) não podem aplicar-se simultaneamente ao mesmo sujeito limita-se a 24 linhas, o que nos permite concluir que Avicena contenta-se em apenas enfatizar pontos que ele considera já bem estabelecidos pela argumentação aristotélica. O filósofo persa apenas sublinha que, caso se supusesse que os dois predicados opostos são simultaneamente verdadeiros, então não haveria enunciação possível (nulla locutio intelligeretur). A consequência impõe-se mesmo se o sofista sustentar uma versão mais restrita do argumento e propor que a contradição significativa seja possível somente 
no caso de alguns predicados. De acordo com Avicena, não há diferença entre sustentar que a contradição é possível em todos os casos e sustentar que ela é possível para um número restrito. As duas afirmações conduzem inexoravelmente ao mesmo resultado. Infelizmente, o argumento de Avicena não foi perfeitamente transmitido pela versão latina medieval. A tradução torna o argumento mais fraco e muito mais dependente de uma leitura prévia de Aristóteles. Eis a passagem central:

Se o nome significasse uma coisa única, como homem, então não homem, que é o seu oposto, jamais significaria o mesmo que homem; de fato, aquilo que homem significa não é o mesmo que aquilo que não homem significa. Se, com efeito, homem significa homem, então, sem dúvida, não homem significaria uma outra coisa, que é pedra ou navio ou preto ou branco ou pesado ou leve e qualquer outra coisa que aquilo que significa o nome homem. (LPP, p. $\left.60^{50}-61^{56}\right)$

O texto não chega a ser ininteligível, mas o argumento de Avicena foi obliterado. A passagem unicamente lembra que a significação dos opostos é diferente e afirma, quase dogmaticamente, a consequência da negação dessa distinção. Falta o núcleo do argumento, ou seja, as razões que conduziriam à conclusão nefasta. A edição latina crítica buscou remediar o problema apoiando-se na edição árabe e deslocando a negação na frase sublinhada. Assim, o texto que os latinos deveriam adivinhar e que nós podemos ler é o seguinte:

Se, com efeito, homem significa não homem, então, sem dúvida, homem significaria uma outra coisa, que é pedra ou navio ou preto ou branco ou pesado ou leve e qualquer outra coisa que aquilo que significa o nome homem.

A modificação aproxima o texto do original árabe, mas o argumento continua ainda mais fraco do que a versão proposta por Avicena, a qual afirma que se homem significasse o mesmo que não homem, então o homem, a pedra, o barco e o elefante (!) seriam uma e mesma coisa. $\mathrm{Ou}$ seja, os latinos poderiam compreender o argumento somente se lessem sua apresentação no texto aristotélico. Ora, frente a essa fraqueza argumentativa, poder-se-ia questionar a real assimilação pelos latinos da versão proposta por Avicena. Não teria a formulação de Aristóteles conhecido 
maior influência do que a aviceniana, sendo razões para isso a proximidade entre os textos e o caráter falho da tradução latina do LPP?

Para finalizar, gostaríamos de responder a essa questão por meio de algumas observações acerca das especificidades da defesa aviceniana. Como veremos, elas representam elementos ausentes ou pouco salientes do texto aristotélico, mas que não deixaram de influenciar os pensadores latinos medievais.

Nossa primeira observação diz respeito às três formulações do PNC que encontramos em Aristóteles. Com efeito, Avicena acredita não precisar da chamada formulação psicológica, limitando-se à ontológica e à lógica (LPP, p. 56 $\left.6^{70-76}\right)$. De acordo com o Estagirita, não é possível ocorrer engano acerca do PNC, pois, para isso, dever-se-ia afirmar que duas proposições contraditórias são verdadeiras, o que é impossível (1005b2931 e LUKASIEWICZ, 2000, p. 99). Para Avicena, ao contrário, o erro é possível quando motivado por certos fatores. Por exemplo, quando, dada a constatação factual de que alguns sábios sustentam uma proposição como verdadeira enquanto outros, tidos por não menos sábios, afirmam sua falsidade. Nesse caso, algumas pessoas, incapazes de dar razão a uma das partes, acreditam na verdade de ambas as proposições contraditórias ( $L P P$, p. 592124). Essa constatação leva Avicena a falar de dois tipos de negadores do primeiro princípio: o sofista, cujo objetivo é a disputa, e o perplexo (erroneus, na tradução latina), que se deixa enganar pela diversidade das opiniões dos sábios. O primeiro deve ser refutado, ao passo que o segundo deve ser instruído por argumentos que mostrem ser a conjunção das duas proposições algo não significativo. Ou seja, Aristóteles não apenas defende a verdade do PNC, mas também a impossibilidade de haver erro e engano a seu respeito. Já Avicena afirma algo mais restrito, mostrando que as pessoas devem conhecer o princípio para reconhecerem a verdade de outras proposições. Ele não afirma, todavia, que as pessoas necessitam reconhecer ter esse conhecimento para poderem reconhecer a verdade de outras proposições, tal como não é necessário que tenham consciência que Barbara é uma forma válida para realizarem argumentos com essa forma. Assim, a defesa do princípio é a demonstração de que certas proposições são condição de possibilidade do discurso. Pode ocorrer que certas pessoas neguem o princípio, mas isso é um erro que pode ser corrigido pelo filósofo e apenas por ele (LPP, p. 6390-92). 
Uma segunda diferença entre os dois autores diz respeito à noção de substância. O Estagirita é frequentemente recriminado por haver lançado mão de sua concepção de substância durante a argumentação, de tal sorte que não aceitar a doutrina da substância é recusar o PNC. A argumentação de Gama teria, então, aproximadamente a seguinte estrutura: começa por formular a necessidade de uma ciência do ser enquanto ser (Gama 1), restringe o escopo da referida ciência a uma investigação acerca da substância (Gama 2) para finalmente utilizar a noção de essência, parte importante da doutrina da substância, no argumento de Gama 4. Sem nos pronunciarmos sobre o caráter controverso dessa reconstrução, limitemo-nos a constatar que a crítica jamais poderia ser endereçada a Avicena, na medida em que o filósofo persa de forma alguma apela à teoria da substância. Se ele pode se passar dessa noção, isso deve-se basicamente ao seu modo de interpretar a estrutura da metafisica. Para ele, a referida disciplina não se limita a investigar a substância e suas propriedades, mas deve ainda demonstrar a existência de Deus, o qual não é uma substância. Logo, se a metafísica é a ciência do ser enquanto ser e se Deus é ser, mas não substância, então os princípios dessa disciplina não podem dizer respeito exclusiva ou principalmente à substância $(L P P, \mathrm{p}$. $\left.63^{10}-64^{14}\right)$, pois tudo o que é demonstrado internamente a uma ciência deve ser entendido como recaindo sob a noção que apresenta o subiectum da disciplina.

Um terceiro ponto de eventual desacordo residiria na caracterização do primeiro princípio como um acidente do ser enquanto ser. Ainda que o texto aviceniano seja bastante próximo do aristotélico, poder-se-ia pensar que a caracterização do primeiro princípio como um acidente (accidentia - 'awârid) do ser afastaria os dois autores e abriria espaço para as famosas críticas de Averróis. Ora, ainda que as críticas do pensador andaluz sejam formuladas precisamente no seu comentário a Gama, não é esse o aspecto da teoria aviceniana visado. Ademais, o próprio Aristóteles oscila caracterizando o princípio ora como atributo (1003a20) ora como acidente do ser (1061b4).

Como último ponto, assinalemos uma passagem que atesta que a refutação do sofista não se limita ao nível do discurso significativo e verdadeiro, mas engloba também a dimensão prática da existência humana. Avicena escreve: 
E é preciso que enviemos o estúpido (stolidum) ao fogo, pois ele sustenta que o fogo e o não fogo são idênticos, e que batamos nele com uma vara para fazê-lo sentir dor, pois ele sustenta que a dor e a não dor são idênticas, e que retiremos dele a comida e a bebida, pois ele sustenta que comer e não comer, beber e não beber são idênticos. (LPP, p. 62 $\left.2^{85-89}\right)$

Ainda que o argumento esteja presente no texto aristotélico, ele não recebe grande atenção. Ora, a sua discussão pelos latinos atesta a ênfase aviceniana. Consideremos dois exemplos. Com efeito, ao procurar provar que as noções primeiras são indemonstráveis, Duns Scotus reivindica duas autoridades que concordam ao dizer que não devemos resistir a todas as evidências sensíveis. Ainda que não se trate de um argumento em favor do PNC, mas do par "necessário e possível”, o núcleo da argumentação é o mesmo: o que a experiência sensível torna manifesto pode escapar a toda demanda de justificação e vence qualquer tipo de dúvida. Eis o argumento:

Em razão disso deve ser aceito como algo evidente (per se notum) que há contingência entre os entes - e aquele que o nega, carece de algo dado através dos sentidos e das penas; e assim Avicena ensina na sua Metafísica que se deve expor ao fogo aqueles que negam o que manifesto aos sentidos e que afirmam ser idêntico o queimar e o não queimar (DUNS SCOTUS, p. 49117-21).

Duns Scotus não o diz, mas os vocábulos "sentidos" e "penas" provêm da tradução latina dos Tópicos (ARISTOTELES LATINUS, 1969, p. 1813-17 e $105 \mathrm{a}^{3-7}$ ) o que resulta em uma curiosa maneira de inserir o argumento aviceniano no âmbito da teoria aristotélica da demonstração e da evidência.

$\mathrm{O}$ argumento de Avicena é igualmente retomado por Alberto Magno em sua Suma de Teologia, quando da comparação entre o modo de argumentar do teólogo e do filósofo.

Assim o metafísico não discute com aquele que nega tudo, mas apenas com aquele que concede algo, por exemplo que os nomes tenham significação, mas não infinita ou contraditória, provando a partir de seus princípios e de outras coisas diversas teses. Com aquele que nega isso, afirmando terem os nomes significação infinita e contraditória, o 
[metafísico] não discute por meio de palavras, mas de fatos, como afirma Avicena no Livro IV da sua Metafísica. Não resta mais nada a fazer a não ser levar ao fogo os adversários da verdade, pois, segundo eles, estar no fogo e não estar no fogo é a mesma coisa (1978, p. 207-16).

A citação é evidentemente incorreta, misturando as obras de Aristóteles e Avicena.Todavia, a correção deve ser feita não no sentido proposto pelos editores modernos de Alberto, que pretendem ler: "ut dicit ARISTOTELES in IV METAPHYSICAE suae". O erro não está no filósofo citado, mas no capítulo da obra. A leitura correta do texto deveria ser, portanto: "ut dicit AVICENNA in I METAPHYSICAE suae".

1 O presente artigo é parte de minha tese de doutorado. Duas razões levaram-me a retomálo para apresentá-lo em um colóquo de filosofia medieval cuja tema foi escolhido em homenagem a Balthazar Barbosa Filho. Em primeiro lugar, por ter sido um dos últimos artigos que discuti com ele. Em segundo, mas mais importante, porque o artigo deve muito às aulas e artigos de Balthazar. Destaco apenas aqueles que me fizeram repensar mais de uma vez a primeira versão desse trabalho: BARBOSA FILHO (1999, 2003, 2004 e 2005).

${ }^{2}$ A divisão dos argumentos é proposta por Bonitz (1949), p. 188-198 e 216 e é seguida, por exemplo, por Tricot e Ross. Sem entrar nos detalhes dessa divisão textual, limitemo-nos a constatar que as discussões contemporâneas tratam antes do PNC que do PTE. Para um levantamento das interpretações concorrentes, consulte-se CASSIN e NARCY (1989), sobretudo p. 264-265 para a defesa dos princípios. Nossa análise concentrar-se-á exclusivamente nas obras de Avicena com tradução latina medieval. Para a tradução moderna dessa obra:AVICENNA, 2007.

3 Sobre o percurso intelectual de Lukasiewicz, veja-se a apresentação de Zaslawsky à tradução francesa de LUKASIEWICZ (1972). Sobre os aspectos propriamente filosóficos de Lukasiewicz, CAUJOLLE (1970) p. 47-72. A influência do livro de Lukasiewicz para a história da filosofia na Polônia é tratada por POUIVET (1999) Consulte-se ainda LE BLANC que resume as principais críticas de Lukasiewicz a Aristote.

${ }^{4}$ LUKASIEWICZ (2000) p. 160: “Tout comme il nous est impossible d'affirmer avec certitude qu'il existe des objets constructionnels non contradictoires, nous n'avons pas de garantie non plus quant à l'existence des objets concrets non contradictoires." O capítulo 5, fornece vários exemplos de contradições, mas seu argumento principal repousa na ontologia de Meinong. Para as relações entre Lukasiewicz e Meinong, ver SIMONS (1989) onde Meinong é apresentado como um dos precursores das lógicas plurivalentes.

5 LUKASIEWICZ (1970g): “The history of logic must be written anew, and by an historian who has a thorough command of modern mathematical logic." Não se deve, contudo, tomar

doispontos, Curitiba, São Carlos, vol. 7, n. 1, p.171-205, abril, 2010 
as críticas metológicas endereçadas a Prantl como demonstração da falta de estima ou da pouca importância que Lukasiewicz nutria pelo trabalho do historiador alemão. Na verdade, a obra de Prantl constitui uma das fontes principais dos textos analisados por Lukasiewicz.

${ }^{6}$ LUKASIEWICZ 1970b, p. 126-127: "For in the conditional in terms of which this thesis is expressed, "if A is b at instant $\mathrm{t}$, then it is true at every instant earlier than $t$ that $\mathrm{A}$ is $\mathrm{b}$ at $t$ ", we can assign such values to variables " $A$ ", " $b$ ", and " $t$ " that its antecedent changes into a true sentence and its consequence into an indeterminate one, that is, into a sentence having the third true value. This always happens when the cause of the fact that $\mathrm{A}$ is $\mathrm{b}$ at a future instant $t$ does not yet exist today. A conditional whose antecedent is true and consequent indeterminate cannot be accepted true; for truth can imply only truth. The logical argument which seems to support determinism falls decisively."

7 Dito de modo mais preciso, Lukasiewicz não chama o terceiro valor de "indeterminado". Em On determinism, limita-se a dizer que as proposições indeterminadas possuem esse valor, mas confessa não possuir nome para caracterizá-lo. É em Philosophical remarks on many-valued systems of propositional logic que ele cunha um nome "the possible" (p. 166). Para uma apresentação mais detalhada do problema do determinismo em Lukasiewicz, ver:TRZESICKI 1989.

8 O artigo data dos anos 1922-23. Para a posição posterior do autor, ver LUKASIEWICZ, 1970f. Quanto às mudanças de posição do autor, consulte-se RESCHER 1993, p. 8-9. O primeiro capítulo dessa obra é consagrado a uma história das lógicas plurivalentes.

9 O argumento aqui apresentado é adaptado da seguinte passagem da lógica: "Quant aux Maximes évidentes, comme celle, qui porte, que les grandeurs égales à une même grandeur, sont égales entre elles, il y en a des Propres à la Science, comme quand on dit, que toute grandeur est ou communicante ou séparée; il y an a de Communes, comme quand on dit, que sur toute chose ou l'affirmation ou la négation se trouve véritable. Les Communes s'approprient dans les Sciences particulières; car on ne dit pas dans la Géométrie, que toute chose est ou égale ou non égale, mais plutôt, toute grandeur; quelquefois on les approprie des deux côtés tout ensemble, comme quand ils disent, que toute grandeur est ou raisonnable ou sourde." AVICENA, 1559, p. 219-220.

${ }^{10}$ A idéia é classica e apresentada de modo claro por Proclus: "The axioms are common to all sciences, although each uses them in the fashion appropriate to its own subject-matter."

\section{Referências bibliográficas}

ALBERTUS MAGNUS. 1890. Liber I Perihermeneias. Revisa et locupletata cura et labore Augusti Borgnet. Opera Omnia. Paris:Vivès.

1978. Summa theologiaer sive de Mirabili scientia Dei. Edidit D. Siedler, W. Kübel et H. G.Vogels. Opera Omnia 34/1. Monasterii Westfalorum: Aschendorf. 
ALEXANDRI APHRODISENSIS. 1847. Comentarius in libros Metaphysicos Aristotelis. Recensuit Hermanus Bonitz. Berolini: G. Reimer. ARISTOTELES LATINUS. 1969. Topica. Translatio Boethii, fragmentum recensionis alterius et translatio anonyma. Edidit L. Minio-Paluello. Paris: Desclée de Brower.

AVICENA. 1977. Liber de Philosophia Prima sive Scientia Divina. Édition critique de la traduction médiévale par S. van Riet, introduction doctrinale par G.Verbeke. Leiden: Brill, 3 vols (1977, 1980, 1983). Citado como LPP. 1559. Logique, édition Vattier. Paris. 1508. Logyca. Venise. 2007. Libro della Guarigione, Le Cose Divine di Avicenna (Ibn Sina), a cura di A. Bertolacci. Turin: UTET.

BARBOSA FILHO, B. 1999. Saber, Fazer e Tempo: uma nota sobre Aristóteles. In: ROCHA, E. M. et alii. Verdade, Conhecimento e Ação. Ensaios em homengam a Guido Antônio de Almeida e Raul Landim Filho. São Paulo: Loyola, p. 15-24.

2003. Nota sobre a contingência. In: WRIGLEY, M. B. e SMITH, P. O Filósofo e sua História: uma homenagem a Oswaldo Porchat. Campinas: Coleção CLE, p. 183-198.

2004. Nota sobre o conceito aristotélico de verdade. Cadernos de História e Filosofia das Ciências. Campinas, v. 13, n. 2, p. 233-243.

2005. Aristóteles e o princípio da bivalência. Revista Analytica, v. 9 , n. 1, p. 173-184.

BERTOLACCI, A. 2006. The Reception of Aristotle's Metaphysics in Avicenna's Kitab al-Sifa. A milestone of Western Metaphysical Thought. Leiden: Brill.

BOLTON, R. 1994. Aristotle's conception of metaphysics as a science. In: SCALTSAS T. et alii (org). Unity, identity, and explanation in Aristotle's Metaphysics. Oxford: Clarendon Press. 
BONITZ, H. 1949. Commentarius in Aristotelis Metaphysicam. Bonn: G. Olms.

BORKOWSKI, L. 1970. Jan Lukasiewicz: Selected works. Amsterdam: North-Holland Publishing Company.

CASSIN, B. E NARCY, M. 1989. La décision du sens. Le livre Gama de la Métaphysique d'Aristote. Introduction, texte, traduction et commentaire. Paris:Vrin.

CAUJOLLE, F. 1970. Logique et philosophie chez Jan Lukasiewicz. L'age de la raison 3 , p. 47-72.

CRAIG, W. L. 1988. The problem of divine foreknowledge and future contingents from Aristotle to Suarez. Leiden: Brill, p 1-3.

FREDE, M. 1974. Die Stoische Logik. Göttingen:Vandenhoeck \& Ruprecht.

1987. Stoic vs. Aristotelian Syllogistic. In: FREDE, M. Essays in Ancient Philosophy. Minneapolis: University of Minneapolis Press, p. 99-124.

HAACK, S. 1974. Deviant logic. Some philosophical issues. Cambridge: Cambridge University Press.

HOUSER, R. E. 1999. Let them suffer into the truth: Avicenna's remedy for those denying the axioms of thought. American Catholic Philosophical Quarterly, 73, p. 107-133.

JOÃO DUNS SCOTUS. 1966. Lectura in primum sententiarum. Opera omnia ... edita praeside P. Carolo Balic. vol. XVII. Civitas Vaticana: Typis polyglottis Vaticanis.

KNEALE, W. E KNEALE, M. 1984. The development of logic. Oxford: Clarendon Press.

LE BLANC, O. Lukasiewicz, Aristote, and contradiction. Disponível em: www.fmag.unict.it/PolPhil/Lukas/LeBlanc.html Acesso em 16/02/2010 


\section{4}

LEAR, J. 1980. Aristotle and the logical theory. Cambridge: Cambridge University Press.

LIVESEY, S. J. 1989. Theology and science in the fourteenth century. Three questions on the unity and subalternation of the sciences from John of Reading's Commentary of Sentences. Leiden: Brill.

LUKASIEWICZ, J. 1970a. Farewell lecture by professor Jan Lukasiewicz, delivered in the Warsaw University Lecture Hall on March 7, 1918. In: BORKOWSKI. 1970, p. 84-86.

1970b. On determinism. In: BORKOWSKI. 1970, p. 110128.

1970c. On the history of the law of bivalence. Reproduzido no apêndice de LUKASIEWICZ. 1970f, p. 153-178.

1970d. On the history of the logic of propositions. Translated by S. McCall. In: BORKOWSKI. 1970, p 197-217.

1970e. On three-valued logic. In: BORKOWSKI. 1970, p.

87-109.

1970f. On variable functors of propositional arguments. In: BORKOWSKI. 1970, p. 311-324.

1970g. Philosophical remarks on many-valued systems of propositional logic. Translated by H. Weber. In: BORKOWSKI. 1970, p. 153-178.

1972. La syllogistique d'Aristote dans la perspective de la logique formelle moderne. Présentation et traduction F. Zaslawsky. Paris: Armand Colin.

1992. Sur le principe de contradiction chez Aristote. Présentation et traduction par B. Cassin et M. Narcy. In: Rue Descartes 1, p. 9-32. 2000. Du principe de contradiction chez Aristote. Traduction D. Siroka, préface de R. Pouivet. Cahors: l'Eclat.

MAROTH, M. 1989. Ibn Sînâ und die Peripatetische "Aussagenlogik". Leiden: Brill. 
MUELLER, I. 1978. An Introduction to Stoic Logic. In: RIST, J. M. The stoics. Berkeley: University of California Press, p. 1-26.

POUIVET, R. 1999. Lukasiewicz: de l'aristotélisme autrichien à l'aristotélisme polonais. Philosophies, vol. 26, n. 2, p. 263-277.

PRANTL, C. 1997. Geschichte der Logik. Reimpressão Hildesheim:

Georg Olms Verlag, 4 vol.

PROCLUS. 1970. A commentary on the first book of Euclid's Elements.

Translated with introduction and notes by G. R. Morrow. Princeton: Princeton University Press.

RESCHER, N. 1993. Many-valued logic. Gower House: Gregg revivals.

SIMONS, P. 1989. Lukasiewicz, Meinong, and many-valued logic. In: SZANIAWSKI, 1989, p. 249-292.

SZANIAWSKI, K. 1989. The Vienna circle and the Lvov-Warsaw school. Dordrecht: M. Nijhoff.

TRZESICKI, K. 1989. Lukasiewicz logic of tenses and the problem of determinism. In: SZANIAWSKI, 1989, p. 293-312.

URQUHART, A. 1986. Many-valued logic. GABBAY, D. e GUENTHNER, F. Handbook of philosophical logic, vol. 3: Alternatives to classical logic. Dordrecht: Reidel Publishing Company, p. 71-116. 